\title{
CORRECTIONS
}

\section{Chronic exertional compartment syndrome}

In this Easily Missed article by Ronald S Paik and colleagues, two errors in the name of one of the authors persisted from

Cite this as: BMJ 2013;346:f544

submission through to publication (BMJ 2013;346:f33, doi:10.

1136/bmj.f33). The second author's name is Douglas A Pepple,

๑ $\odot$ BMJ Publishing Group Ltd 2013

not Douglas Pepples. 